\title{
Amphibian species richness across environmental gradients
}

\author{
Earl E. Werner, David K. Skelly, Rick A. Relyea and Kerry L. Yurewicz
}

E. E. Werner (eewerner@umich.edu), Dept of Ecology and Evolutionary Biology, Univ. of Michigan, Ann Arbor, MI 48109, USA. D. K. Skelly, School of Forestry \& Environmental Studies, Yale Univ., New Haven, CT 06511, USA. - R. A. Relyea, Dept of Biological Sciences, Univ. of Pittsburgh, Pittsburgh, PA 15260, USDA. - K. L. Yurewicz, Biological Sciences, Plymouth State Univ., Plymouth, NH 03264, USA.

\begin{abstract}
Large-scale field patterns are a fundamental source of inferences on processes responsible for variation in species richness among habitats. We examined species richness of larval amphibian communities in 37 ponds over seven years on the Univ. of Michigan's E. S. George Reserve. Ordination of the community incidence matrix indicated a strong major axis of variation in species associations that was correlated with pond hydroperiod, surface area and forest canopy cover. Communities were significantly nested with those species found in ponds with high canopy cover, small area and short hydroperiod being nested subsets of those found in ponds with contrasting characteristics. Presence of fish had strong negative effects on species richness; relaxation of this effect also was apparent when fish were extirpated from ponds by drought. We employed a model selection analysis to identify the most appropriate statistical model for predicting the long-term average species richness of these ponds from local abiotic and biotic (predator and competitor density) factors. A model including only the abiotic factors was overwhelmingly superior for the anurans; hierarchical partitioning indicated that area and canopy cover alone accounted for over $70 \%$ of the independent effects of predictor variables. The global model including both abiotic and biotic factors was the best supported model for the caudates, and correspondingly hierarchical partitioning suggested that area, hydroperiod, invertebrate predators and caudate biomass all accounted for $9-16 \%$ of the independent effects. Overall, biotic factors accounted for much less of the variation in species richness than abiotic factors. The patterns in larger, open-canopy ponds provided little evidence of competitive effects on species richness, though there were patterns consistent with competitive effects in small, closed-canopy ponds. The unusual temporal and spatial extent of these data enabled us to critically evaluate ideas regarding patterns in larval amphibian communities, and the effects of area, disturbance (hydroperiod) and productivity (canopy cover) on species richness of these communities. These results have important implications to the conservation of amphibian species richness in freshwater wetlands, which are among the most threatened ecosystems worldwide.
\end{abstract}

Understanding processes responsible for variation in species richness among habitats is a fundamental goal of ecology, and large-scale field patterns are a fertile source for hypotheses concerning these processes. Such pattern analysis has a venerable history in ecology, in particular analyses of the distributions of both individual taxa and species richness along environmental gradients. These patterns provide inferences concerning the traits of species associated with performance differences along the gradients, and the factors affecting species coexistence and community assembly (Connell 1975, Ricklefs and Schluter 1993, Wellborn et al. 1996).
Moreover, in contrast to the conduct of much of experimental ecology, such patterns and the inferences they provide are clearly at relevant scales for assessing the interactions of local and regional processes which contribute to community assembly, and for addressing many important applied and conservation problems.

Freshwater ponds provide an excellent system for exploring such patterns; they are arrayed along well defined gradients of size, disturbance regime (e.g. hydroperiod), and productivity with corresponding patterns in community composition (Wellborn et al. 1996, Waide et al. 1999). The amphibian communities 
along such gradients, in particular, have received considerable attention (Heyer et al. 1975, Wilbur 1984, Wellborn et al. 1996). These studies have focused primarily on the effects of pond hydroperiod and associated changes in the communities of potentially interacting species, but rarely have the above gradients and biotic factors been quantified for a given set of ponds. Consequently our understanding of the factors responsible for variation in amphibian species richness remains limited. Moreover, survey studies typically have been short-term or "snapshot" estimates of patterns in species richness, and therefore we have little appreciation of the variation in richness over time among ponds, or the factors that contribute to the long-term average richness of these ponds. Because many other taxa change in similar ways along these axes of environmental variation (Wellborn et al. 1996), and these gradients are conceptually parallel to those in other systems, we might expect that models developed for amphibian communities will be of broader relevance.

In this paper, we examine patterns in species richness of larval amphibian communities in 37 ponds over seven years. Our overall objective was to evaluate patterns in relation to multiple environmental variables and potential correlates of species interactions. We first asked if species presences differed from a null model of random placement of species in ponds, if communities were significantly nested, and where on environmental gradients major transitions in species turnover occurred. We then determined whether long-term patterns in the species richness of ponds were more effectively predicted by average environmental characteristics of ponds or the biomass of larval predators and competitors (i.e. interactions among species). We formulated a series of models predicting species richness of ponds that incorporated either or both abiotic and biotic factors, and used a model selection analysis to ask which relationships were best supported. Because many of these characteristics of ponds were not independent, we employed hierarchical partitioning to identify the extent to which each predictor variable was independently related to the response variable. These results enable us to identify the factors associated with the patterns of amphibian species richness on complex environmental gradients, and pose hypotheses concerning the mechanisms responsible. The results further illustrate the importance of long-term data to provide context for the development of metacommunity theory, and to help managers evaluate conservation options.

\section{The system}

We studied amphibian communities inhabiting 37 wetlands on the Univ. of Michigan's E. S. George
Reserve (hereafter ESGR). The ESGR is a 525 ha tract located about $40 \mathrm{~km}$ northwest of Ann Arbor, Michigan $\left(42^{\circ} 28^{\prime} \mathrm{N}, 84^{\circ} 00^{\prime} \mathrm{W}\right)$ that has been fenced and administered as a restricted access preserve since 1930.

The ESGR wetlands (hereafter termed ponds) include a number of kettlehole ponds, swamps, marshes and Sphagnum bogs ranging up to 7 ha in area (Fig. 1). The terrestrial vegetation of the ESGR is dominated by grasslands and hardwood forest (chiefly Quercus, Carya and Acer as canopy dominants). There has been a steady succession of grasslands to forest following the clearing of much of the area by the 1850 s and cessation of agricultural activity in the first quarter of this century (from about 30\% forest cover in 1940 to $80 \%$ in 1995, Skelly et al. 1999, Werner et al. unpubl.).

Seventeen amphibian species have been recorded breeding on the ESGR, including representatives of three frog and three salamander families (Table 1). Two species were not collected in our survey; Plethodon cinereus is entirely terrestrial and Acris crepitans went locally extinct on the ESGR in 1971 due to a drought (Collins and Wilbur 1979). Thus, our sampling included 15 species. Of these 15, one was not distinguished from Ambystoma laterale (A. tremblayi, which is a gynogenetic triploid hybrid of the $A$. jeffersonianum complex with one set of chromosomes from $A$. jeffersonianum and two from $A$. laterale, and is quite difficult to distinguish based on external characteristics, Uzzell 1964). Two other of the species, Rana palustris and Hemidactylum scutatum, were rare in our collections.

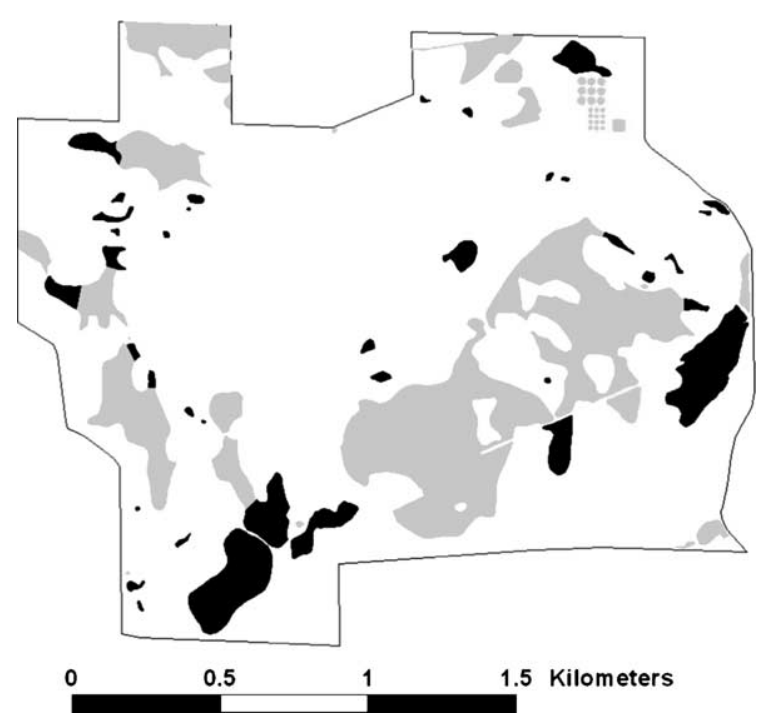

Fig. 1. Map of the E. S. George Reserve showing ponds that were sampled in black. Other wetland areas (few of which support amphibian larvae) are shaded in the lighter color. 
Table 1. Amphibian species reported on the E. S. George Reserve.

\begin{tabular}{|c|c|c|}
\hline Family & Species & Common name \\
\hline \multirow{5}{*}{$\begin{array}{l}\text { Bufonidae } \\
\text { Hylidae }\end{array}$} & Bufo americanus & \multirow{5}{*}{$\begin{array}{l}\text { American toad } \\
\text { cricket frog } \\
\text { gray tree frog } \\
\text { spring peeper } \\
\text { chorus frog }\end{array}$} \\
\hline & Acris crepitans & \\
\hline & Hyla versicolor & \\
\hline & Pseudacris crucifer & \\
\hline & P. triseriata & \\
\hline \multirow[t]{5}{*}{ Ranidae } & Rana catesbeiana & bullfrog \\
\hline & R. clamitans & green frog \\
\hline & R. pipiens & leopard frog \\
\hline & R. sylvatica & wood frog \\
\hline & R. palustris & pickerel frog \\
\hline \multirow[t]{5}{*}{ Ambystomatidae } & Ambystoma laterale & blue-spotted \\
\hline & A. maculatum & spotted \\
\hline & & salamander \\
\hline & A. tigrinum & $\begin{array}{l}\text { tiger } \\
\text { salamander }\end{array}$ \\
\hline & A. tremblayi & $\begin{array}{l}\text { Tremblay's } \\
\text { salamander }\end{array}$ \\
\hline \multirow[t]{2}{*}{ Plethodontidae } & $\begin{array}{l}\text { Hemidactylium } \\
\text { scutatum }\end{array}$ & $\begin{array}{l}\text { four-toed } \\
\text { salamander }\end{array}$ \\
\hline & Plethodon cinereus & $\begin{array}{l}\text { red-backed } \\
\text { salamander }\end{array}$ \\
\hline Salamandridae & $\begin{array}{l}\text { Notophthalmus } \\
\text { viridescens }\end{array}$ & eastern newt \\
\hline
\end{tabular}

\section{Methods}

\section{Pond characteristics}

Surface areas of the ESGR ponds were digitized from aerial photographs (scale 1:3000) taken during the winter of 1995 (when forest canopy did not obscure ponds). In several of the marshes large central areas are dry and support terrestrial vegetation; hence these regions were deleted from the pond area. The scale employed with the photographs was ground-truthed from measurement of artificial ponds and buildings on the site. Pond areas ranged between 10 and $53400 \mathrm{~m}^{2}$ $(\bar{x} \pm$ se, $6068 \pm 2117)$, though the frequency distribution was skewed to smaller ponds $\left(73 \%<2500 \mathrm{~m}^{2}\right)$.

Depth gauges were established in all ponds in the fall of 1998 and water levels were recorded at $\sim 1.5-2$ week intervals between late March and November. We estimated pond hydroperiod as the average number of days that a pond held water divided by the number of days censused (ponds that held water in November typically did not dry during the winter). If a pond contained water on one census date and was dry on the next, it was considered to have dried midway between the dates. Prior to installing the depth gauges, we recorded status of the ponds when we sampled in May and July and noted if ponds were dry in the fall. Average pond hydroperiod ( $\%$ of days the pond held water) ranged from 30 to $100 \%$ ( $\overline{\mathrm{x}}$ across ponds $62.5 \pm$ $3.5 \%)$. Individual ponds, however, varied substantially annually; in the extreme, ponds could range from permanent in some years to holding water for only a few months in others.

Canopy cover was quantified using a spherical densiometer (Halverson et al. 2003). A minimum of five sites in each pond were chosen to take readings. The first site was the perceived center of the pond and the four subsequent sites were determined by moving in each of the four cardinal directions from the center site towards a position $\sim 2 \mathrm{~m}$ from the pond shore. In larger ponds $(\mathrm{n}=26)$, more than 5 sites were needed to accurately describe canopy cover. In these ponds, readings were made every 5 or $10 \mathrm{~m}$ depending on pond size along transects through the N-S and E-W axis of the pond. Four readings were taken at each sampling site, one facing each cardinal direction. For all ponds, canopy cover was calculated by first averaging the four readings taken at each site (site mean), then averaging all site means for a pond. Canopy cover of the ponds ranged from $<1$ to $93 \%(\overline{\mathrm{x}}=59 \pm 5 \%)$.

\section{The amphibian survey}

The amphibian survey was conducted over seven consecutive years (1996-2002). We sampled larval amphibians and their predators twice each year to estimate densities of both the spring- and summerbreeding amphibians. We sampled the third week in May and July (with the exception of 1996 when we sampled 5/20-6/7 and 7/6-7/15; and 1997 when we sampled 6/9-6/24 and 7/28-8/2). Samples were taken by "pipe sampling", dipnetting and seining. The pipe sampler was constructed of a $76 \mathrm{~cm}$ length of $36 \mathrm{~cm}$ diameter aluminum pipe fitted with handles at the top; the pipe thus sampled $0.1 \mathrm{~m}^{2}$ of water column and sediments. The sample was taken by quietly approaching an area and quickly thrusting the pipe through the water column and into the sediments to seal the sample area. Nets $(22 \times 27 \mathrm{~cm}$ with a $1 \times 2 \mathrm{~mm}$ mesh size $)$ were employed to remove all animals from the sampled water column and the first few centimeters of the sediments. Circular sweeps of the net were taken until at least 10 consecutive sweeps were made without capturing any animals (see Mullins et al. 2004 for an evaluation of these techniques).

Sampling effort varied with size of the pond: in small ponds $\left(<750 \mathrm{~m}^{2}\right)$ we took 20 pipe samples haphazardly distributed across representative microhabitats in the ponds. In medium-sized ponds $\left(>750 \mathrm{~m}^{2}\right.$ but $<1500 \mathrm{~m}^{2}$ ), we took $30-40$ pipe samples across representative microhabitats. In the largest ponds and marshes $\left(>1500 \mathrm{~m}^{2}\right)$, we sampled along two transects consisting of 20 pipe samples each. Transect locations were the same each year and traversed representative microhabitats in the pond. Pipe samples were always 
separated by at least $2 \mathrm{~m}$. All amphibians, fish, and invertebrate predators collected in the pipe samples were preserved in the field.

Following completion of the pipe sampling, we dipnetted the pond for the equivalent person-minutes as the number of pipe samples taken from the pond (i.e. if 40 pipe samples were taken we dipnetted for 40 person-minutes) employing the same nets used to clear the pipes. In cases where density estimates were employed in analyses and species were only obtained in the dipnet samples, we estimated density from dipnet catch per unit effort. These estimates were obtained from regressions of pipe density estimates against individuals captured per person-minute dipnetting for all cases where individuals of that taxon were captured by both techniques in a pond. Because of the highly episodic nature of amphibian populations, we had enormous variation in density estimates for each family within a pond across sampling dates so data points from a pond are not clustered at any position on the density/ catch per unit effort graph (i.e. density estimates are not confounded with sampling effort, pond characteristics, etc). To ensure adequate sample sizes and ranges for these relationships, we grouped species by family. Regressions were constrained to go through the origin and were highly significant (ambystomatids: $\mathrm{R}^{2}=0.72$, $\mathrm{p}<0.001$, hylids: $\mathrm{R}^{2}=0.88, \mathrm{p}<0.001$, ranids: $\mathrm{R}^{2}=$ $0.76, p<0.001$, newts: $\left.R^{2}=0.88, p<0.001\right)$ with the exception of the American toad $\left(\mathrm{R}^{2}=0.26\right.$, ns). Sample sizes were small for the toad, and so we used the relationship for hylids to estimate densities where necessary. In ponds with deeper water $(>1 \mathrm{~m}, 5$ water bodies), standard sampling was supplemented with two hauls of an $8-\mathrm{m}$ bag seine in the deeper water. This method permitted us to sample areas that were too deep for the pipe samplers. We recorded all individuals obtained from the dipnetting in the field, and preserved all invertebrate predators and $10-30$ individuals of a species or taxon group for the amphibians.

Amphibians in the samples were identified to species, snout-vent length measured, and Gosner stage recorded. All potential predators of amphibians (including fish, Odonata, Hemiptera, Coleoptera, Araneae, Hirudinea) were identified to species where reliable keys were available (most taxa), or to genus when this was not possible (e.g. a number of dytiscid beetle larvae), and measured (length or head width depending on taxon). For analyses of predator effects, we selected a subset of the invertebrates that we expected to be important predators on amphibian larvae based on literature accounts, ultimate size, and our experience. Among the odonates we included all members of the Aeshnidae, Cordulidae, Gomphidae, and Libellulidae. We also included the Belostomatidae, Notonectidae, Nepidae, and the Megaloptera. Finally, among the beetles we included larvae of the larger dytiscid (Dytiscus, Hydaticus, Colymbetes) and hydrophilid species (Hydrochara, Dibolocelus), and the larger adult dytiscids (Dytiscus, Hydaticus, Colymbetes, Acilius, Graphoderus, Agabus, Rhantus, Ilybius).

We employed predator biomass in analyses in order to scale the presence of larger predators in accord with their abilities to prey on a wider size range, and to consume more, of the amphibian larvae. Samples of invertebrate predators were dried $\left(60^{\circ} \mathrm{C}\right.$ for $\left.24 \mathrm{~h}\right)$ to obtain length-dry weight regressions. Due to the small number of specimens available for some taxa, or lack of adequate keys, we in some cases lumped species into broader taxonomic and/or morphologically similar categories (usually family-level). Length-weight regressions also were obtained for ambystomatid salamanders (Yurewicz unpubl.), the newt (Fauth unpubl.), and anuran larvae (individual species regressions were so similar that a composite regression was used for all species; $\left.\mathrm{R}^{2}=0.99, \mathrm{~F}_{1,156}=18,670, \mathrm{p}<<0.001\right)$.

\section{Statistical procedures}

In this report, we are concerned with larval amphibian presence/absence patterns in the ponds. We assessed sampling efficiency by first examining species accumulation curves (Colwell and Coddington 1994) and associated statistics employing EstimateS, ver. 7 (http://viceroy.eeb.uconn.edu/estimates). All individuals were pooled from the pipe, dip and seine samples for a pond in a given year, and species accumulation curves constructed based on the distribution of species among individuals (sampling effort). In cases where we reached our self-imposed collection limit while dipnetting and individuals could not be identified to species in the field, the total number of individuals dipnetted was distributed among species in the ratios obtained from the preserved sample. We employed the Chao2 biascorrected richness estimator to estimate "true" species richness of ponds.

We further computed 95\% detection threshold curves as a function of larval density. Since both pipe sampling and dipnetting contributed to detection ability, we can pool the data by employing the regressions described above to predict numbers of individuals collected per unit effort dipnetting. The mean slope of the relationships for the four families (weighted by number of species) was $0.85+0.1$ indicating that the number of individuals collected per min of dipnetting was equivalent to the number typically collected in 1.2 pipe samples. Since personminutes dip netting was set equal to the number of pipe samples taken, this means that our effective sampling effort was just over twice that represented by the number of pipes (i.e. if we took 40 pipe samples, the effective sampling effort was 88 pipe equivalents). 
We could therefore use pipe equivalents to estimate detection probabilities.

The basic patterns in species distributions were summarized by an incidence matrix, which provides the site by species presence/absence values. We constructed a 14 species $\times 36$ pond (one pond never had any species) incidence matrix and considered a species present if it was encountered in that pond during any of the seven years. To test whether these incidences differed from a null model of random placement of species in ponds, we employed the approach of Leibold and Mikkelson (2002). We first ordered rows and columns of the incidence matrix by ordination (reciprocal averaging), such that sites with the most similar species lists and species with the most similar distributions were closest together. Employing the software provided by Leibold and Mikkelson (2002), we then tested this matrix to determine if there was a strong dominant axis of variation, and if so, whether the matrix was characterized by species turnover or nested subsets, and whether there was strong clumping of species boundaries.

\section{Model formulation}

The incidence matrix presented patterns in the association of individual species with different environmental characteristics and each other based on cumulative presences. We also were interested in the patterns of amphibian species richness in ponds, and identifying the local factors that influenced species richness. It is not clear what time scale actually best captures regulation of community structure in this system, but because of incidental presences and effects of extreme years (in some case resulting in the loss of fish) cumulative richness could be problematic. Therefore, we asked what the relation was between long-term average environmental and biotic conditions and the longterm average species richness of a pond. We employed a model selection approach to identify the most appropriate statistical model for predicting amphibian species richness from local factors. Formulating models for total amphibian species richness of ponds with biotic factors is difficult as these communities are composed of species occupying two trophic levels; i.e. carnivorous caudates (salamanders) and herbivorous/detritivorous anuran larvae. Consequently, we formulated models separately for these two orders. The local abiotic variables included in the models were pond hydroperiod, area and forest canopy cover. Local biotic variables included biomasses of anuran larvae, caudate larvae and invertebrate predators (all per $\mathrm{m}^{2}$ ). We employed May biomasses in these analyses reasoning that this biomass density was the most likely to influence both the spring breeders and the early larval phase of the summer breeders. Most species in this community were spring breeders and even summer breeders, when small, overlapped to some extent with these species. Moreover, the average biomass of anuran larvae across all ponds was 2.4-fold higher in May than in July ( $\mathrm{t}$-test, $\mathrm{t}=2.7$, $\mathrm{DF}=60, \mathrm{p}=0.01)$, and the ambystomatid salamanders all breed in the spring.

All three of the abiotic variables are known to be associated with species richness of amphibian communities and there are biologically plausible mechanisms by which these factors could influence both anurans and caudates (Skelly et al. 1999, Van Buskirk 2005). Biotic factors have a somewhat different interpretation for the two taxa. For anurans, biomass represents potential competitive effects, and caudate and invertebrate biomass represent potential predatory effects (these were maintained as separate variables because of potential differences in their modes of predation and the fact that caudate biomass can often swamp that of invertebrate predators in many of the ponds). For caudates, invertebrate biomass represents potential predators, caudate biomass potential competitors (the latter variable, however, could include effects generated both through competition and intraguild predation), and anuran biomass potential prey.

The global models for both taxa therefore included all six of these local abiotic and biotic variables. We then formulated two further models that postulated only the effects of local abiotic or biotic effects were important, and therefore each of these models included the three relevant variables. The models were formulated for ponds without fish (or years without fish). We had a relatively small number of ponds with fish for all seven years, and the impact of fish renders many relationships on environmental variables quadratic that are otherwise linear.

We employed $\mathrm{AIC}_{\mathrm{c}}$, a bias-corrected version of Akaike's information criterion, to rank models according to the strength of support from the data (Burnham and Anderson 2002). The best model is that with the lowest $\mathrm{AIC}_{\mathrm{c}}$ value, and we employed Akaike weights to assess the likelihood of alternative models. Akaike weights also were used to estimate parameter values and their variances employing a model averaging approach (Burnham and Anderson 2002). Model averaged estimates and SE's were calculated and 95\% confidence intervals employed to assess the magnitude of the effect. We concluded that there was an effect if the confidence interval excluded 0 .

The Akaike model selection procedure seeks the single best supported predictive model, but this approach does not identify those variables most likely to influence variation in the response variable (species richness in our case). Abiotic and biotic predictor variables were often significantly intercorrelated. Such multicollinearity makes it difficult to identify variables that have independent effects on the response variable. 
In order to identify important potential causal variables having independent effects on species richness we employed hierarchical partitioning (Mac Nally 2002, Quinn and Keough 2006). Hierarchical partitioning employs goodness of fit measures $\left(R^{2}\right.$ in a multiple regression setting) and averages the incremental improvement in fit by the addition of a given variable to all of the possible models $\left(2^{\mathrm{k}}\right.$ models for $\mathrm{k}$ predictor variables) with that variable compared to the equivalent model without that variable. Using this method one can partition explanatory power for each predictor variable into independent effects and those due to joint effects with other variables (i.e. those that cannot be unambiguously associated with the variable in question). For both anurans and caudates we included all six abiotic and biotic variables listed above in these analyses. We further employed a method randomizing the data suggested by Mac Nally (2002) to statistically evaluate which predictor variables should be retained (analyses conducted in R, R Development Core Team 2006). For some analyses we also employed principal components analyses to extract orthogonal measures of site heterogeneity. In all cases the first principal component was employed and accounted for a large fraction of the variation (and was the only component retained by the broken-stick criterion, Jackson 1993).

\section{Results}

\section{Sampling effectiveness}

While detection errors are an inevitable part of surveying occupancy, our analyses suggest that we had excellent power to detect species overall. Estimators of species richness from sampling effort typically converge on the observed species number when all species are represented by two or more individuals in the collection (Colwell and Coddington 1994). This was the case in $64 \%$ of our 219 pond - year combinations. Cases with singletons (species represented by a single individual in the sample) that are adequately sampled versus inadequately sampled can look substantially the same (Colwell and Coddington 1994), so in these cases we employed the Chao2 richness estimator in EstimateS to estimate the species richness of the pond that year. In only $5 \%$ of the total number of pond-year combinations did the theoretically estimated number of species exceed the actual number sampled by $>0.5$. Further, there was no relation $\left(\mathrm{R}^{2}=4 \times 10^{-6}\right)$ between the fraction of records in a pond that were singletons and the sampling effort in that pond (measured as pond area/no. of pipe samples taken, which varied over a 212fold range because we were unable to sample very large marshes with the same effort as small ponds). Finally, the detection threshold analysis indicated that if larvae were assumed (as a first approximation) to be binomially or Poisson distributed, our $95 \%$ detection threshold for a species occurred at densities on the order of 1 larva per $3.3 \mathrm{~m}^{2}$ in the larger ponds.

\section{Community coherence}

There were consistent patterns in species distributions across the ESGR ponds; the incidence matrix exhibited strong coherence with species associations differing significantly from random placement of species (Fig. 2). The row ordination of the matrix (Fig. 2) describes the dominant axis of variation in species composition among ponds and these ordination scores were positively correlated with pond area and hydroperiod, and negatively correlated with canopy cover ( $\mathrm{p}<0.001$ for all regressions).

Species ranges across the dominant axis exhibited significant turnover (i.e. species tended to replace each other from site to site, $\mathrm{p}<0.05)$. Further, range boundaries were significantly clumped (Morisita's index $=2.50, \mathrm{p}<0.001)$. Species replacements occurred primarily at the extremes of the major axis of variation (Fig. 2), with species boundaries strongly clumped near these extremes. This strong clumping was associated with pond canopy cover (below) at the upper extreme of the matrix and with predatory fish and permanent water at the lower extreme.

Communities also were significantly nested (i.e. communities of species-poor ponds tended to be subsets of those of species-rich ponds $(p<0.01)$. There was a strong tendency for communities in ponds with high canopy cover, small area and short hydroperiod to be nested subsets of those with the contrasting characteristics (Fig. 2). The incidence matrix was constituted of cumulative species presences and included cases of a species found only incidentally in a pond. Identical results for all tests were obtained if we constructed the incidence matrix with a more stringent species presence criterion (i.e. requiring a species to be present in the pond at least two of the seven years).

The matrix ordination places species closest together that have the most similar distributions and this ordering exhibited strong clustering by family. The ranids exhibited a tendency to be associated with more permanent water and fish. The glaring exception was Rana sylvatica, which was separated from the other ranids because it was found in shorter hydroperiod and closed-canopy ponds. The ranids were followed by the newt and then a cluster of all three hylids. These are smaller species with shorter larval periods that can inhabit more temporary environments, though still largely open-canopy environments. The next cluster includes the ambystomatid salamanders and 


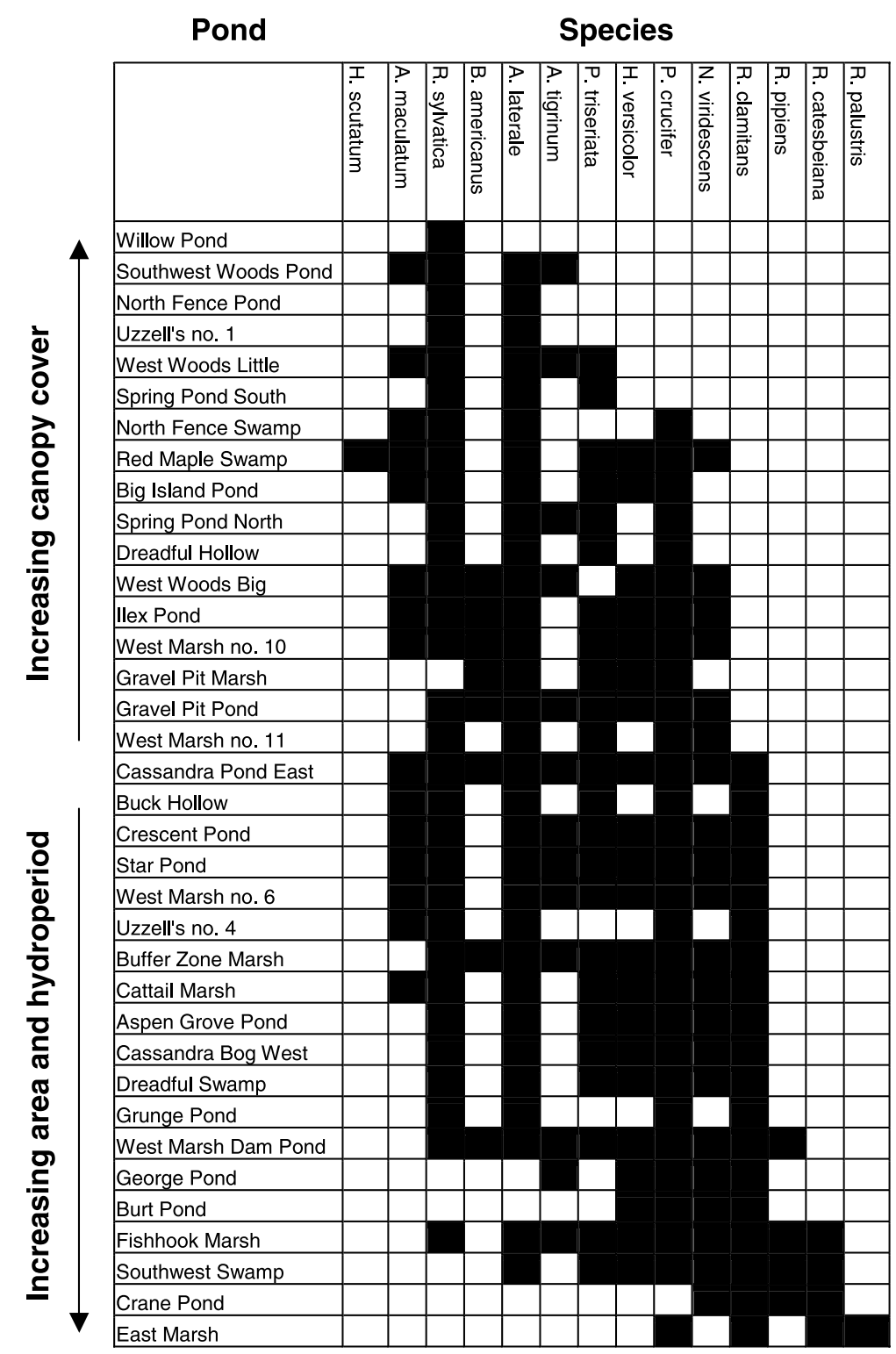

Fig. 2. Incidence matrix for the E. S. George Reserve ponds. Solid areas indicate that a species was present in that pond at least once over the seven-year survey. The matrix is ordered by the ordination method of Leibold and Mikkelson (2002) and species associations significantly differed from random placement of species subject to the constraints 1) that the null matrix had the same numbers of ones and zeros and that no rows or columns had only zeros $(p<0.001)$, or 2$)$ that row and column sums were maintained as in the original matrix $(\mathrm{p}<0.001)$. Environmental factors associated with ponds were significantly correlated with the ordination values in the directions indicated by the arrows.

$R$. sylvatica, which use a wider variety of habitats, but as a group are the species that can also inhabit closedcanopy ponds. Bufo americanus is also included in this group although this species is a bit enigmatic, as it rarely inhabits closed-canopy ponds and has a large number of embedded absences in the matrix (Fig. 2).

\section{Factors associated with amphibian species richness}

Over the 7-year survey period, the average number of amphibian species found in a pond was $3.25 \pm 0.26$, considerably fewer than the 14 possible species. The 
patterns in mean species richness were related to each of the three environmental gradients associated with ponds. The relations between species richness and all three gradients were significantly quadratic (Fig. 3).

What factors are responsible for patterns in richness? A decline in average species richness for larger, and longer hydroperiod, ponds was associated with the presence of predatory fish (Fig. 3). Four species of fish were sampled in the ESGR ponds, with the most common species being the mudminnow, Umbra limi, and the redside dace, Phoxinus eos. Two ponds also contained the golden shiner, Notemigonus crysoleucus, and one pond contained the stickleback, Culaea inconstans. Thus, while the ESGR ponds lacked the fish diversity found in local lakes, even this depauperate fauna of smaller-bodied fish apparently had a substantial impact on the species richness of amphibians.

The impact of fish on amphibian richness was made clear by a "natural experiment". The ESGR experienced a strong drought commencing in the late summer and fall of 1998 (Hoerling and Kumar 2003); most ponds held water in July of 1998 but by the end of that fall nearly $80 \%$ of the ponds were dry. Of the five ESGR ponds that contained resident (reproducing) fish populations prior to 1998, three dried for the first time in nearly 30 years due to this drought, extirpating the fish. Elimination of fish from these three ponds had a dramatic impact on amphibian species richness (Fig. 4); initial species richness was below the ESGR average, but after 1998 species richness climbed steeply to an average of eight species making them among the richest ponds on the ESGR. Species that never chorused in these ponds when they contained fish began to chorus in them (e.g. R. sylvatica and Pseudacris triseriata), in some cases the spring immediately following extirpation of fish. Amphibian species richness in ponds that continued to harbor fish populations showed no change.

If we excluded ponds (or pond-years) with fish, the relationships between amphibian species richness and all local variables were best fit by linear relationships (Fig. 3). We used this set of ponds for the modelselection analysis and the model averaged parameter estimates. Results for anurans were clear; the best supported model included only the abiotic variables $\left(\mathrm{R}^{2}=0.81\right.$, Table 2$)$. The Akaike weight for this model was 0.97 indicating that the model had a $97 \%$ chance of being the best model given the data. The biotic model was poorly supported by the data and had an $\mathrm{R}^{2}$ of only 0.48. Model averaged parameter estimates indicated that only area and canopy cover were different from 0 (Table 3).

For caudates the best supported model was the global model including both abiotic and biotic variables $\left(\mathrm{R}^{2}=0.55\right.$, Akaike weight of 0.52$)$, though this model in general was a much weaker model than that for anurans (Table 2). Further, there was substantial
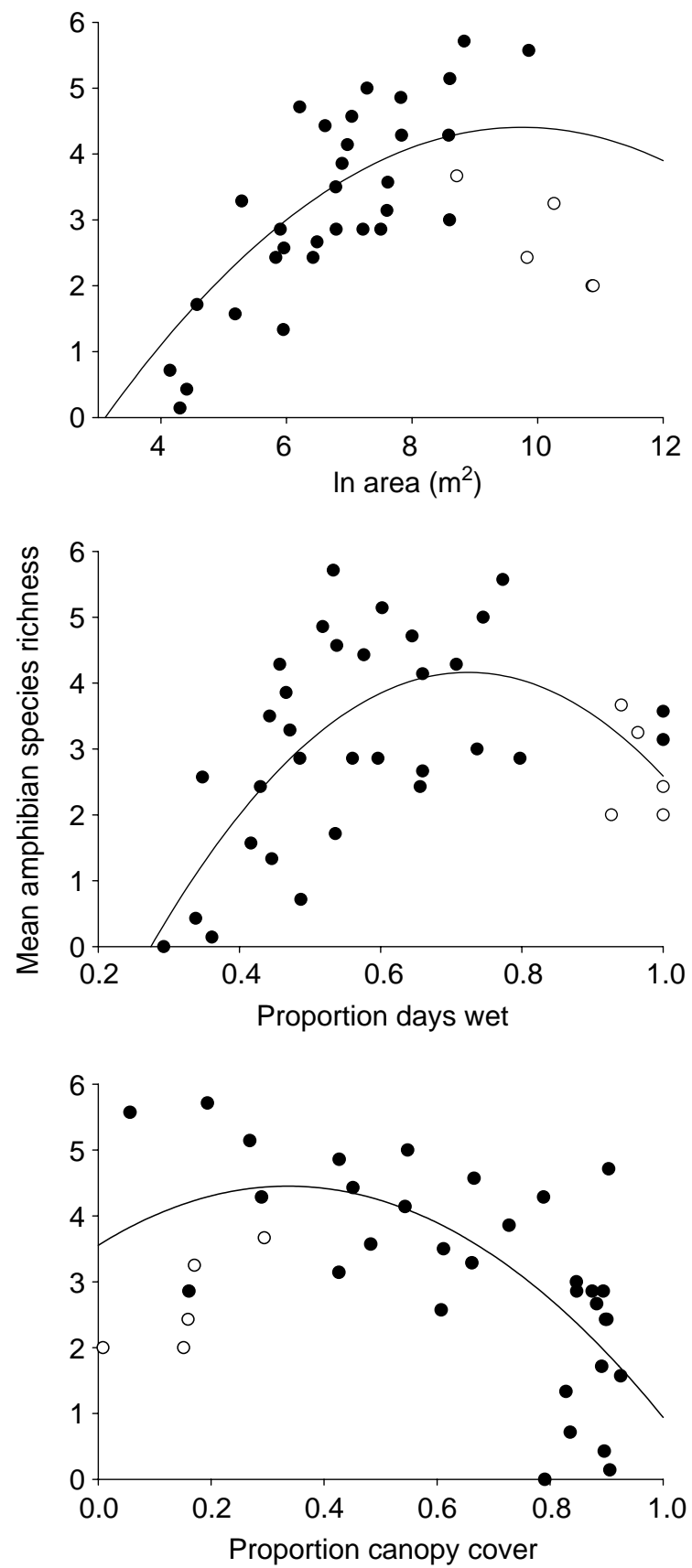

Fig. 3. Mean amphibian species richness of the E. S. George Reserve ponds as a function of pond area, hydroperoid and canopy cover. Closed symbols represent ponds lacking fish; open symbols represent ponds with fish (for three of these for the years before extirpation of fish). For area, a quadratic equation provided a significantly better fit than linear (quadratic; $\mathrm{R}^{2}=0.56, \mathrm{~F}_{1,34}=21.4, \mathrm{p}<0.001$; quadratic vs linear, $\left.\mathrm{F}_{1,34}=9.3, \mathrm{p}=0.005\right)$. This was also the case for hydroperoid (quadratic; $\mathrm{R}^{2}=0.41, \mathrm{~F}_{1,34}=11.6, \mathrm{p}<0.001$; quadratic vs linear, $\mathrm{F}_{1,34}=13.1, \mathrm{p}<0.001$ ), and canopy cover (quadratic; $\mathrm{R}^{2}=0.40, \mathrm{~F}_{1,34}=11.5$, $\mathrm{p}<0.001$; quadratic vs linear, $\left.\mathrm{F}_{1,34}=6.1, \mathrm{p}=0.025\right)$. 


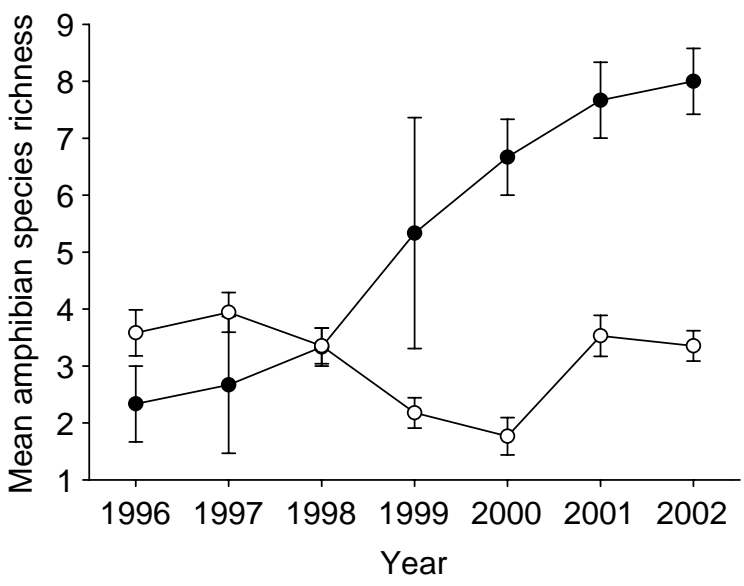

Fig. 4. Mean amphibian species richness of E. S. George Reserve ponds across years. Closed symbols represent ponds that lost fish in the fall of 1998 or during 1999 (West Marsh Dam Pond, Fishhook Marsh and Southwest Swamp); open symbols are all other ponds.

support for all models indicating a relatively large amount of uncertainty regarding the best model (Table 2). Model averaged parameter estimates and confidence intervals indicated only area was significantly different from 0 , though caudate and invertebrate predator biomass were nearly significant (Table 3 ).

These analyses therefore indicated strong support for a statistical model of abiotic factors for anurans and inclusion of these variables in the model for caudates. However, it is not clear from these analyses whether all of these variables are independently contributing to variation in species richness, or if variables are included in the model because they contribute to the overall best fit due to correlations with causal variables. Further, it is not clear if all independently contributing variables are included in the selected models. The three environmental variables were moderately collinear (variance inflation factors ranging from 2.1-4.5); smaller ponds exhibited more extensive forest canopy cover, and, in general, possessed shorter hydroperiods. Thus, hydroperiod was positively $\left(r=0.74, \quad F_{1,35}=41.3\right.$, $\mathrm{p}<0.001)$, and canopy cover negatively $(\mathrm{r}=0.78$, $\left.\mathrm{F}_{1,35}=52.6, \mathrm{p}<0.001\right)$, correlated with pond area, and canopy cover negatively correlated with hydroperiod $\left(\mathrm{r}=0.52, \mathrm{~F}_{1,35}=13.1, \mathrm{p}<0.001\right)$. Caudate and anuran biomass were not significantly correlated with any of the other variables. However, invertebrate predator biomass was significantly positively correlated with area $\left(\mathrm{r}=0.66, \quad \mathrm{~F}_{1,31}=24.1, \mathrm{p}<0.001\right)$ and hydroperiod $\left(\mathrm{r}=0.49, \quad \mathrm{~F}_{1,31}=9.8, \quad \mathrm{p}=0.004\right)$ and significantly negatively correlated with canopy cover $\left(\mathrm{r}=0.63, \mathrm{~F}_{1,31}=20.8, \mathrm{p}<0.001\right)$.

To identify the extent to which these variables were independently related to species richness, we employed hierarchical partitioning. The results of the analyses largely reinforced those of the model selection exercise with specific exceptions. For anurans, area and canopy cover alone accounted for $71 \%$ of the independent effects of all variables (Table 4). This is consistent with the model selection analysis, which indicated greatest support for the abiotic model and significant model

Table 2. Model selection results for predicting average species richness of anurans and caudates in ponds.

\begin{tabular}{|c|c|c|c|c|c|c|}
\hline & Number of parameters & $\mathrm{n}$ & Residual SS & $\mathrm{AIC}_{\mathrm{C}}$ & $\Delta_{\mathrm{i}}$ & $\mathrm{W}_{\mathrm{i}}$ \\
\hline \multicolumn{7}{|l|}{ Anuran model } \\
\hline Abiotic variables & 5 & 33 & 11.3 & -23.1 & 0.0 & 0.97 \\
\hline Biotic variables & 5 & 33 & 30.1 & 9.2 & 32.3 & 0.00 \\
\hline $\begin{array}{l}\text { Global model } \\
\mathrm{R}^{2} \text { of the best } \text { model }=0.81\end{array}$ & 8 & 33 & 10.3 & -16.4 & 6.7 & 0.03 \\
\hline \multicolumn{7}{|l|}{ Caudate model } \\
\hline Abiotic variables & 5 & 33 & 8.5 & -32.6 & 1.3 & 0.27 \\
\hline Biotic variables & 5 & 33 & 8.6 & -32.2 & 1.8 & 0.22 \\
\hline Global model & 5 & 33 & 6.1 & -34.0 & 0.0 & 0.52 \\
\hline $\mathrm{R}^{2}$ of the best model $=0.55$ & & & & & & \\
\hline
\end{tabular}

Table 3. Model-averaged parameter values for anurans and caudates. Bold values are those where $95 \%$ confidence intervals excluded 0.

\begin{tabular}{lcccccc}
\hline Parameter & Area & Canopy cover & Hydroperiod & Invertebrate predators & Caudate biomass & Anuran biomass \\
\hline Anurans & & & & & & \\
$\quad$ estimate & $\mathbf{0 . 4 0}$ & $\mathbf{- 2 . 1 4}$ & 0.36 & 0.005 & 0.0007 & 0.00002 \\
SE & 0.13 & 0.62 & 0.77 & 0.008 & 0.0008 & 0.00002 \\
Caudates & & & & 0.001 & 0.00002 \\
$\quad$ estimate & $\mathbf{0 . 2 2}$ & 0.45 & 0.72 & 0.007 & 0.0007 & 0.00002 \\
SE & 0.11 & 0.53 & 0.64 & & \\
\hline
\end{tabular}


Table 4. Hierarchical partitioning of the variance for the 64 models in each case associated with the 6 predictor variables for anurans and caudates. The negative values for joint effects indicate that a variable is acting as a suppressor variable (Chevan and Sutherland 1991). Asterisks indicate values significant by the randomization procedure.

\begin{tabular}{lccc}
\hline Variable & Independent & Joint & Total \\
\hline Anurans & & & \\
Area & $0.29^{*}$ & 0.43 & 0.72 \\
Canopy cover & $0.29^{*}$ & 0.40 & 0.69 \\
Hydroperiod & 0.08 & 0.19 & 0.27 \\
Invertebrate predators & $0.14^{*}$ & 0.31 & 0.45 \\
Caudate biomass & 0.01 & 0.03 & 0.04 \\
Anuran biomass & 0.006 & 0.005 & 0.011 \\
Caudates & & & \\
Area & $0.16^{*}$ & 0.13 & 0.29 \\
Canopy cover & 0.04 & 0.05 & 0.09 \\
Hydroperiod & $0.11^{*}$ & 0.15 & 0.26 \\
Invertebrate predators & $0.11^{*}$ & 0.15 & 0.26 \\
Caudate biomass & 0.09 & -0.04 & 0.05 \\
Anuran biomass & 0.03 & -0.02 & 0.01 \\
\hline
\end{tabular}

averaged parameter estimates for area and canopy cover. Hierarchical partitioning, however, also indicated that invertebrate predator biomass accounted for $17 \%$ of the independent effects (Table 4). Area, canopy cover and invertebrate predator biomass were significant by the randomization technique.

For caudates, the model selection procedure indicated that the global model was the best supported model. Congruent with this result, hierarchical partitioning indicated that four of the predictor variables contributed between 9 and $16 \%$ of the independent effects, and three of these were significant by the randomization technique (area, hydroperiod and invertebrate predator biomass, Table 4).

Additional analyses clarify some of the effects of these predictor variables. The strong independent effect of canopy cover on anuran richness suggested by both the model selection and hierarchical partitioning analyses can be illustrated by dividing ponds into two categories, open- and closed-canopy $(\mathrm{n}=19$ and 14 respectively). We made this division at $>$ or $\leq 75 \%$ cover (Fig. 3). We regressed mean anuran richness for open- and closed-canopy ponds on the first principal component (PC1) from a factor analysis including pond area and hydroperiod (Fig. 5). Across the composite hydroperiod-area gradient, closed-canopy ponds averaged two fewer species of anurans than opencanopy ponds (open-canopy mean $=3.27 \pm 0.25$ species, closed-canopy $=1.2 \pm 0.2$ ).

Pond area was identified by the model selection and hierarchical partitioning analyses as having strong independent effects on variation in both anuran and caudate richness. We can gain some insight into how pond area, per se, may affect species richness by comparing mean and cumulative species richness (all

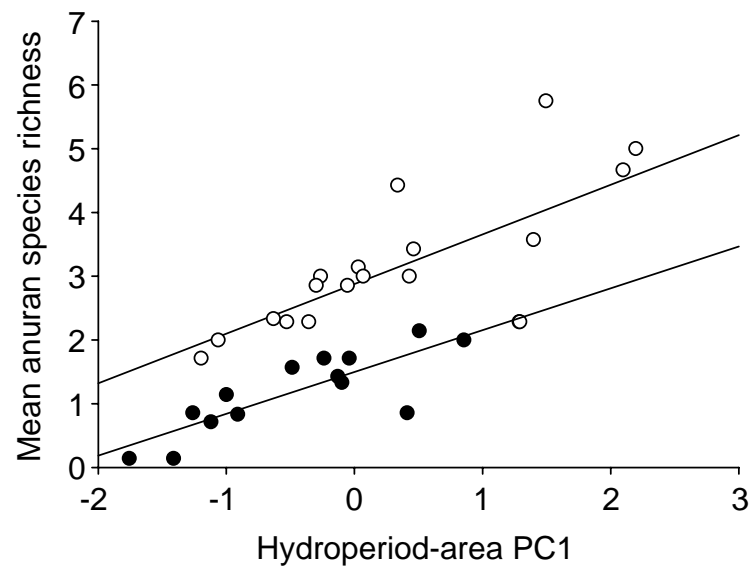

Fig. 5. Mean anuran species richness for open- (open symbols) and closed- (closed symbols) canopy ponds on the E. S. George Reserve as a function of the first principal component accounting for the variation in hydroperiod and area of these ponds. PC1 accounted for $81 \%$ of the variance and factor loadings for both area and hydroperiod were 0.90 , no other principal component was retained by the brokenstick criterion (Jackson 1993). Analysis of covariance indicated that the relations were parallel (canopy category $\times \mathrm{PC} 1$ interaction, $F_{1,29}=0.2, p=0.66$ ), but differed significantly in elevation $\left(\mathrm{F}_{1,29}=28.6, \mathrm{p}<0.001\right)$.

amphibians) of ponds. Because closed-canopy ponds encompassed a very limited range of areas $(80 \%<900$ $\mathrm{m}^{2}$ vs a range of 200-53 $000 \mathrm{~m}^{2}$ for open-canopy ponds) and exhibited lower anuran richness, the pattern is most clearly seen by confining analyses to opencanopy ponds. For open-canopy ponds, there was no relation between area and cumulative species richness, whereas there was a strong positive relation between area and mean species richness (Fig. 6). This pattern suggested that habitat diversity or other attributes associated with area per se did not exclude species from using open-canopy ponds. In fact, during 7 years of sampling we found as many species in our smallest open-canopy pond (ten species in Cassandra Pond East, $200 \mathrm{~m}^{2}$, mean richness of 3.3 species) as any pond on the ESGR. Consequently, it appears likely that factors such as population size (and related extinction rates) or the increased variance in hydroperiod associated with smaller pond areas (Werner et al. unpubl.) were responsible for the independent effects of pond area in these relationships.

Hydroperiod contributed only $9 \%$ of the independent effect on species richness of anurans and $21 \%$ on caudates, yet is one of the primary variables amphibian ecologists associate with control of species richness. One way to isolate the signature of hydroperiod is to examine patterns over time. Because of the 19982002 drought, individual ponds varied widely in hydroperiod over time, allowing us to examine the 


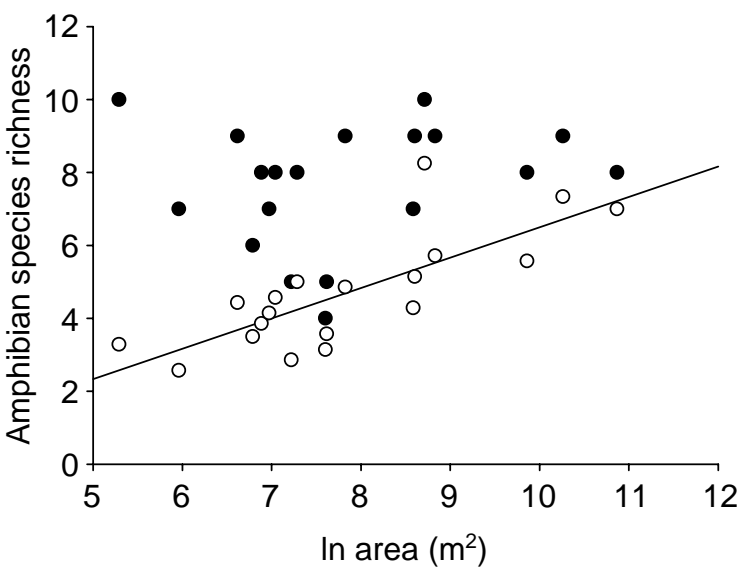

Fig. 6. Cumulative (closed symbols) and mean (open symbols) amphibian species richness of open-canopy E. S. George Reserve ponds with $<75 \%$ forest canopy cover as a function of pond area. The line is the significant linear regression for mean species richness $\left(r=0.78, F_{1,17}=26.2\right.$, $\mathrm{p}<0.001)$, cumulative richness was not significant $(\mathrm{r}=0.16$, $\left.\mathrm{F}_{1,17}=0.45, \mathrm{p}=0.51\right)$.

effects of variation in annual hydroperiod on species richness within a pond (i.e. holding area and canopy cover constant). There was a clear effect of annual variation in hydroperiod on species richness; the number of species in a pond was positively related to hydroperiod across years (average slope of regressions across all 29 ponds where hydroperiod varied was $2.8 \pm$ $0.5, \mathrm{t}=5.5, \mathrm{DF}=28, \mathrm{p}<0.001)$. Because species richness was constrained in closed- vs open-canopy ponds, slopes were significantly different in the two pond types (average slopes of 4.0 and 1.6 for open- and closed-canopy ponds, respectively; t-test, $\mathrm{t}=2.4$, $\mathrm{DF}=27, \mathrm{p}=0.01$ )

The model selection analyses indicated little support for the effect of biotic factors (other than those due to fish), whereas hierarchical partitioning suggested that there were independent effects of invertebrate predators on both taxa. As noted above, invertebrate predator biomass was significantly positively correlated with area and hydroperiod and negatively with canopy cover. Consequently, invertebrate predator biomass was significantly positively correlated with species richness of both anurans $\left(r=0.67, \mathrm{~F}_{1,31}=25.7, \mathrm{p}<0.001\right)$ and caudates $\left(\mathrm{r}=0.51, \mathrm{~F}_{1,31}=10.7, \mathrm{p}=0.003\right)$. We further attempted to assess whether an effect of invertebrate predators could be isolated once variance due to the abiotic gradients was removed. Both amphibian species richness and invertebrate predator biomass were significantly positively correlated with the first principal component (PC1) extracted from the three environmental variables describing ponds (using all ponds without fish; PC1 accounted for $74 \%$ of the variation with hydroperiod and area loading positively (factor loadings 0.81 and 0.94 respectively), and canopy cover negatively (factor loading-0.83)). There was no relation between amphibian species richness residuals and invertebrate predator biomass residuals from PC1 $\left(\mathrm{r}=0.24, \mathrm{~F}_{1,33}=2.1, \mathrm{p}=0.16\right)$. There was considerable variation in both the species composition of amphibians and biomass of predators from year to year in individual ponds, and it is possible that analyses of means could mask effects that were apparent in extreme years. We therefore performed the same analyses as above assuming pond-years were independent data points. There was a significant positive relation between amphibian richness residuals and invertebrate predator residuals, but the variance accounted for was minimal $\left(\mathrm{R}^{2}=0.02, \mathrm{~F}_{1,207}=4.6\right.$, $\mathrm{p}=0.03)$.

There also was little effect of taxon biomass on species richness for either order, suggesting little support for potential competitive effects. To further assess potential competitive interactions on species richness we focused on the anurans; the caudates constitute a different trophic level (but see Petranka and Kennedy 1999, Schiesari 2004) and competitive interactions can be complicated by intraguild predation (Yurewicz 2002). Mean anuran richness was significantly related to PC1 extracted from the environmental variables, but mean anuran biomass was not. We therefore regressed anuran species richness residuals from $\mathrm{PC} 1$ against mean anuran biomass in ponds and these variables were unrelated $\left(\mathrm{F}_{1,30}=1.7, \mathrm{p}=0.2\right)$. This analysis aggregates ponds that may have very different potentials for competitive effects (e.g. openand closed-canopy ponds), and averages across years within ponds that have very different biomasses of anurans. Therefore, we examined the relations using independent pond-years for open- and closed-canopy ponds, and the relationships exhibited different trends for the two pond types. The relationship was significantly positive for open-canopy ponds $(r=0.38$, $\left.\mathrm{F}_{1,131}=21.4, \mathrm{p}<0.001\right)$ and non significant but with a negative slope for closed-canopy ponds. There are, of course, serious statistical concerns in assuming independent pond-years, but the raw data provided in Fig. 7 suggest an upper boundary constraint in closed-canopy ponds (i.e. fewer species are found in years when biomass density of anurans is high).

Analyses of the data points available for individual ponds across years reinforced the above conclusions; for the open-canopy ponds, regressions between species richness and biomass of anuran larvae were positive for 11 ponds, negative for two ponds, and eight exhibited no relation. However, for closed-canopy ponds having multiple years of data, three of the smallest ponds never contained more than one species ( $R$. sylvatica) and the nine others never contained more than one or two species in years of high anuran biomass (Fig. 7). Closed- 


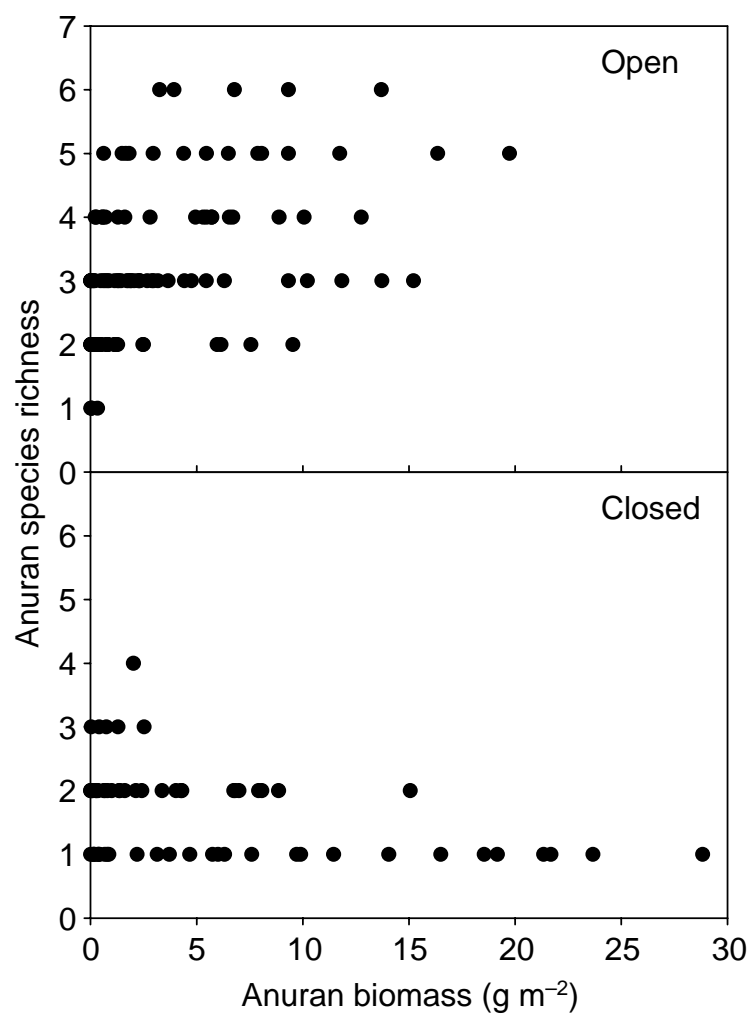

Fig. 7. Anuran species richness of open- and closed-canopy ponds plotted against anuran biomass $\left(\mathrm{g} \mathrm{m}^{-2}\right)$. Data points are individual pond-years. The data are truncated at $30 \mathrm{~g}$ $\mathrm{m}^{-2}$ : this truncation excluded three data points for closedcanopy ponds which ranged to $>80 \mathrm{~g} \mathrm{~m}^{-2}$ and in all cases only one species was in the pond, and one data point for open-canopy ponds at a biomass of just under $50 \mathrm{~g} \mathrm{~m}^{-2}$ with two species in the pond. The latter was a very small pond $\left(\sim 200 \mathrm{~m}^{2}\right)$.

canopy ponds had significantly higher average biomass densities of anuran larvae than open-canopy ponds (means of 8.2 and $4.0 \mathrm{~g} \mathrm{~m}^{-2}$ respectively, t-test, $\mathrm{t}=2.6, \mathrm{DF}=170, \mathrm{p}=0.01)$ and exhibited a wider range in densities (Fig. 7).

\section{Discussion}

Amphibian species richness at the ESGR is strongly patterned; with the exception of the strong effects of fish, our analyses suggest that much of this pattern emerges in response to abiotic variation among ponds. Ordination of the ESGR incidence matrix demonstrated a clear major axis of variation with amphibian richness positively correlated with area and hydroperiod, and negatively with canopy cover of the ponds. The model selection analysis indicated that these average environmental characteristics of ponds were considerably more predictive of species richness than biotic factors, especially for anurans. Further, hierarchical partitioning reinforced these conclusions as the average environmental characteristics of ponds generally had much stronger independent effects on species richness than biotic factors. Importantly, our data are more comprehensive than most studies that attempt inferences on the factors affecting amphibian species richness in terms of both spatial and temporal extent of the study (the lack of which can lead to erroneous conclusions, Skelly et al. 2003), and the estimation of abiotic and biotic variables associated with the ponds.

The impacts of major factors limiting species richness of ESGR ponds at the extremes of the ordinated matrix, fish and canopy closure, were transparent. Species replacements were significantly clumped at the boundary of fish/no fish ponds (permanent/non-permanent water) and again as forest canopy closed over the ponds (Fig. 2 and 3, Wellborn et al. 1996). The effects of fish are in clear concordance with the literature; spatial surveys have widely documented a negative correlation between amphibian species richness and presence of fish (but see Babbitt et al. 2003), e.g. in North America (Collins and Wilbur 1979, Hecnar and M'Closkey 1996, Bradford et al. 1998, Snodgrass et al. 2000a) and Europe (Brönmark and Edenhamn 1994). Further, indirect effects initiated with fish can be a strong determinant of species replacements on these environmental gradients (Werner and McPeek 1994), and fish can have strong traitmediated effects (Werner and Peacor 2003) on amphibian distributions. That is, presence of fish can influence oviposition decisions (or habitat choice) of a number of amphibian species, thus behaviorally excluding them from water bodies (Hopey and Petranka 1994, Rieger et al. 2004, Petranka et al. 2004, Resetarits 2005). On the ESGR, species that were never known to call in ponds with fish began calling in these ponds the spring following extirpation of fish (Petranka et al. 2004).

Forest canopy cover also markedly limited amphibian species richness in ESGR ponds (Fig. 5); these ponds contained only a nested subset of species found in open-canopy, longer hydroperiod ponds (Baber et al. 2004). This effect was essentially due to exclusion of anuran species from closed-canopy ponds. The lone exception to this pattern was $R$. sylvatica, and experimental transplants of anuran larvae across extremes of this gradient on the ESGR have demonstrated that only $R$. sylvatica can grow and survive well in deeply shaded ponds (Werner and Glennemeier 1999, Skelly et al. 2002). Though the effect of canopy cover was one of the strongest signals in our data, it has been relatively little explored in the literature (but see Skelly et al. 1999, 2005, Van Buskirk 2005). 
There are clear mechanisms that may account for the effect of forest canopy cover; canopy cover dramatically affects resource availability and quality as well as abiotic conditions in a pond (Werner and Glennemeier 1999, Skelly et al. 2002, Halverson et al. 2003, Schiesari 2004). C:N ratios of both tadpole gut contents and natural foods indicate that resources are of lower nutritional quality in closed-canopy ponds, and experimental studies suggest that (power-efficiency) tradeoffs often seen in species replacing each other on productivity gradients are responsible for differences in species performance (Schiesari 2004, Schiesari et al. 2006). Further, the influence of canopy cover appears to be strong enough in some cases to lead to local adaptation in species (Relyea 2002, Skelly 2004). The effect of canopy cover is likely restricted to the anurans due in part to the effects of reduced light levels on their resources. The caudates, which in contrast are carnivorous, appear to be relatively unaffected by canopy cover (i.e. largely subsisting on a detritus-based food chain). Given strong effects of forest cover on both the larval and terrestrial phases of a number of amphibian species (Hecnar and M'Closkey 1998, Skelly et al. 1999, 2005, Houlahan and Findlay 2003, Schiesari 2004) the widespread succession of forested landscapes (especially over much of eastern North America) would be expected to have wide-ranging effects on amphibian communities.

Pond area had substantial independent effects on species richness of both taxa. Reports in the literature generally indicate little evidence of a relation between amphibian species richness and pond area (Hecnar and M'Closkey 1996, Snodgrass et al. 2000b, but see Houlahan and Findlay 2003), but the smallest ponds in most of these studies are considerably larger than ours. As noted earlier the contrast in mean and cumulative species richness in these ponds (Fig. 6) suggests that effects of small population sizes and enhanced variation in hydroperiod, were the important factors determining the lower mean richness in smaller ponds. In fact, there is a strong negative relation between extinction rate and pond area on the ESGR, and the variance in hydroperiod increases nonlinearly with decline in mean hydroperiod (Werner et al. 2007). Therefore, because of frequent extinctions in these ponds, spatial context and connectivity between ponds should strongly influence the effect of area, e.g. if isolated from other ponds, pond size could become more important than indicated here.

Perhaps the most widely cited factor influencing amphibian species richness is pond hydroperiod (Skelly 2001, for recent survey studies see Snodgrass et al. 2000a, 2000b, Babbitt et al. 2003). The expectation that amphibian species richness should exhibit a unimodal curve peaking at intermediate hydroperiods was articulated by Heyer et al. (1975) and Wilbur
(1984), and generalized to additional taxa incorporating the role of life history tradeoffs and predator transitions on the hydroperiod gradient by Wellborn et al. (1996). Hydroperiod exhibited the weakest independent signal of the environmental gradients in our data, but the temporal extent of our survey and the increasing disparity between mean and cumulative richness with decline in pond area (Fig. 6) enabled us to show a clear effect of hydroperiod on species richness within a pond. Years of shorter hydroperiods typically excluded the late spring and summer breeders from ponds (Semlitsch et al. 1996). The significant nesting of species in the ESGR amphibian community (Fig. 2) also suggests that the disturbance (hydroperiod) gradient is important because of developmental constraints (larval period, Urban 2004). The constraints of hydroperiod appear to be largely temporary as species requiring longer hydroperiods quickly take advantage of local climatic variation leading to extended hydroperiods in specific ponds. Again, this factor should strongly interact with spatial context or connectivity of the ponds, as extinctions due to climate variation affecting hydroperiod require recolonization from other ponds, and therefore mean richness of a pond will depend on how often this occurs (Werner et al. 2007).

Thus, effects of abiotic factors on amphibian species richness exhibited in our data appear strong and supported by plausible mechanisms. Evidence for the effects of biotic factors on species richness of ponds was less compelling. With the exception of fish, evidence from the field of the impact of predators on amphibian species richness is scant or mixed (Skelly 2001, 2002, but see Smith and Van Buskirk 1995, Fauth 1999). Hierarchical partitioning indicated independent correlations between invertebrate predators and species richness of both anurans and caudates. Since these relationships were strongly positive, potential mechanisms responsible include keystone predator effects or the fact that invertebrate predators were correlated with additional environmental factors that were unmeasured. Van Buskirk (2005) in assessing occurrences of individual species in a European community also found that in three of the four cases where model averaged parameter estimates were significant, correlations with predators were positive. We do not see correlations consistent with strong competitive effects for the anurans in the larger open-canopy (and predator-rich, Schneider and Frost 1996) ponds, suggesting that a keystone predator effect is less likely. The strong behavioral and morphological responses of many amphibian larvae to invertebrate predators indicate that these predators have been a significant selective force on larval traits (Relyea 2001, Van Buskirk and Arioli 2005), and may have density effects or potentially limit certain species (Werner and McPeek 1994, Smith and Van Buskirk 1995, Babbitt et al. 
2003). Experimental work will be required to determine if these correlations actually represent effects of predators. Unfortunately, we were unable to assess the impact of other vertebrate predators that may affect these amphibian communities, e.g. turtles, snakes and raccoons.

Interspecific competition among amphibian larvae has received a great deal of attention, and can have strong effects under controlled experimental conditions (Wilbur 1997, Skelly 2002). However, evidence from the field is scarcer, especially for effects on species richness. There was no signal in our data that competitive effects limited species richness in opencanopy ponds. Species richness relationships were positive with anuran biomass suggesting that the addition of new species simply added biomass without affecting presence of other species, and/or that good years for many species were coincident. Similarly, Van Buskirk (2005) also found that the occurrences of all species in a European community were positively correlated with densities of other species, indicating that if competition was important it was overwhelmed by the positive effects of site quality. In many regards this pattern might be expected in larger open-canopy ponds which are much less likely to be saturated with larvae from the surrounding terrestrial adult population. Moreover, these ponds are generally highly productive (Schiesari 2004).

In contrast, patterns in closed-canopy ponds were consistent with potential competitive effects limiting species composition, and it is possible that such effects could be more prevalent in closed-canopy ponds. First, these ponds as a group are smaller than open-canopy ponds and therefore more likely to achieve very high densities of anuran larvae (mean biomass density 2.4 fold higher than in open-canopy ponds). Second, closed-canopy ponds provide a much poorer resource base for anuran larvae (Schiesari 2004). Third, aside from $R$. sylvatica which can achieve high densities in closed-canopy ponds, most species of anuran larvae appear to perform poorly in these environments potentially making them more vulnerable to competitive effects in these ponds (Werner and Glennemeier 1999, Skelly et al. 2002, 2005, Schiesari 2004). Freidenberg (2003) also has performed intraspecific competition experiments with wood frogs in open- and closed-canopy sections of a pond, and showed that percapita competitive effects were stronger in the closedcanopy section.

In conclusion, community assembly is a function of both local and regional factors. In our system a large amount of local environmental heterogeneity is captured by a single principal component (Urban 2004), which in turn is associated with a large fraction of the variation in species richness between sites. This heterogeneity is generated by gradients in disturbance (hydroperiod), productivity (canopy cover), and pond area, which have important effects on species richness in many taxa (Connell 1975, Ricklefs and Schluter 1993, Waide et al. 1999). It appears that each of these factors or gradients has independent effects on community richness and composition in the amphibians. Our data also suggest that with the exception of those with fish, the effects of species interactions on species richness are more subtle and contingent than the strong sorting effects of these major environmental variables (Skelly 2002). Van Buskirk's (2005) analyses of individual species distributions in a European community also suggest that amphibians are choosing ponds on the basis of their average environmental characteristics and that any effects of species interactions other than those with fish are more subtle. These inferences, of course, are derived from correlations with attendant limitations and should serve primarily in directing experimental work to test for causal relationships.

Long-term survey data are essential to explore the effects of factors influencing patterns in species richness given the problems with snapshot surveys (Skelly et al. 2003). Such data are especially valuable in exploring variation in factors within ponds (i.e. unconfounded by other covarying variables) that change on time scales longer than typical survey studies (e.g. canopy cover), and providing opportunities to use "natural experiments" to discover important interactions otherwise not apparent in snapshots of the system. Despite the large interannual variation in the ESGR amphibian communities, species clearly are limited to certain parts of all of the gradients examined, suggesting the role of tradeoffs at the species level to environmental factors along the gradients (Werner and McPeek 1994, Smith and Van Buskirk 1995, Schiesari 2004). These strong patterns in composition with respect to environmental heterogeneity clearly argue for some level of species sorting or niche assembly (e.g. compared to neutral models of community assembly, Hubbell 2001) and thus aid in defining more precise hypotheses for theories of species richness along complex gradients and metacommunity dynamics. Hopefully, inferences from the above patterns will help in generating hypotheses for direct experimental tests, and in constructing conservation policies regarding freshwater wetlands, which are among the most threatened ecosystems world-wide.

Acknowledgements - We wish to especially thank Chris Davis for his efforts on all aspects of this project from data collection and management to analyses - without his efforts this project would not have been possible, and the many individuals too numerous to list who have participated in collection of the field data, but especially Josh Van Buskirk and Andy McCollum. John Fauth kindly provided the length-weight regressions for the newt. Comments by Josh Van Buskirk, Mike Benard, Shannon McCauley and Emily Silverman 
greatly improved an earlier version of the ms. This work was supported by NSF LTREB grants DEB-9727014 and DEB0454519 .

\section{References}

Babbitt, K. J. et al. 2003. Patterns of larval amphibian distribution along a wetland hydroperiod gradient. - Can. J. Zool. 81: 1539-1552.

Baber, M. J. et al. 2004. The relationship between wetland hydroperiod and nestedness patterns in assemblages of larval amphibians and predatory macroinvertebrates. - Oikos 107: 16-27.

Bradford, D. F. et al. 1998. Influences of natural acidity and introduced fish on faunal assemblages in California alpine lakes. - Can. J. Fish. Aquat. Sci. 55: 2478-2491.

Brönmark, C. and Edenhamn, P. 1994. Does the presence of fish affect the distribution of tree frogs (Hyla arborea). - Conserv. Biol. 8: 841-845.

Burnham, K. P. and Anderson, D. R. 2002. Model selection and multimodel inference: a practical information-theoretic approach. - Springer.

Chevan, A. and Sutherland., M. 1991. Hierarchical partitioning. - Am. Stat. 45: 90-96.

Collins, J. P. and Wilbur, H. M. 1979. Breeding habits and habitats of the amphibians of the E. S. George Reserve, Michigan, with notes on the distribution of fishes. - Occas. Pap. Mus. Zool. Univ. Mich. 686: 1-34.

Colwell, R. K. and Coddington, J. A. 1994. Estimating terrestrial biodiversity through extrapolation. - Philos. Trans. R. Soc. Lond. B. 345: 101-118.

Connell, J. H. 1975. Some mechanisms producing structure in natural communities: a model and evidence from field experiments. - In: Cody, M. L. and Diamond, J. (eds), Ecology and evolution of communities. Harvard Univ. Press, pp. 460-490.

Fauth, J. E. 1999. Identifying potential keystone species from field data - an example from temporary ponds. - Ecol. Lett. 2: 36-43.

Freidenburg, L. K. 2003. Spatial ecology of the wood frog, Rana sylvatica. - PhD thesis. Univ. of Connecticut, Storrs, CT.

Halverson, M. A. et al. 2003. Forest mediated light regime linked to amphibian distribution and performance. - Oecologia 134: 360-364.

Hecnar, S. J. and M'Closkey, R. T. 1996. Regional dynamics and the status of amphibians. - Ecology 77: 2091-2097.

Hecnar, S. J. and M'Closkey, R. T. 1998. Species richness patterns of amphibians in southwestern Ontario ponds. - J. Biogeogr. 25: 763-772.

Heyer, W. R. et al. 1975. Tadpoles, predation and pond habitats in the tropics. - Biotropica 7: 100-111.

Hoerling, M. and Kumar, A. 2003. The perfect ocean for drought. - Science 299: 691-694.

Hopey, M. E. and Petranka, J. W. 1994. Restriction of wood frogs to fish-free habitats - how important is adult choice. - Copeia 1023-1025.

Houlahan, J. E. and Findlay, C. S. 2003. The effects of adjacent land use on wetland amphibian species richness and community composition. - Can. J. Fish. Aquat. Sci. 60: $1078-1094$.

Hubbell, S. P. 2001. The unified neutral theory of biodiversity and biogeography. - Princeton Univ. Press.

Jackson, D. A. 1993. Stopping rules in principal componentsanalysis - a comparison of heuristic and statistical approaches. - Ecology 74: 2204-2214.

Leibold, M. A. and Mikkelson, G. M. 2002. Coherence, species turnover, and boundary clumping: elements of meta-community structure. - Oikos 97: 237-250.

Mac Nally, R. 2002. Multiple regression and inference in ecology and conservation biology: further comments on identifying important predictor variables. - Biodiv. Conserv. 11: 1397-1401.

Mullins, M. L. et al. 2004. Assessment of quantitative enclosure sampling of larval amphibians. - J. Herpetol. 38: $166-172$.

Petranka, J. W. and Kennedy, C. A. 1999. Pond tadpoles with generalized morphology: is it time to reconsider their functional roles in aquatic communities? - Oecologia 120: $621-631$.

Petranka, J. W. et al. 2004. Identifying the minimal demographic unit for monitoring pond-breeding amphibians. - Ecol. Appl. 14: 1065-1078.

Quinn, G. P. and Keough, M. J. 2006. Experimental design and data analysis for biologists. - Cambridge Univ. Press.

Relyea, R. A. 2001. Morphological and behavioral plasticity of larval anurans in response to different predators. - Ecology 82: 523-540.

Relyea, R. A. 2002. Local population differences in phenotypic plasticity: predator-induced changes in wood frog tadpoles. - Ecol. Monogr. 72: 77-93.

Resetarits, W. J. 2005. Habitat selection behaviour links local and regional scales in aquatic systems. - Ecol. Lett. 8: 480-486.

Ricklefs, R. E. and Schluter, D. 1993. Species diversity in ecological communities. - Univ. of Chicago Press.

Rieger, J. F. et al. 2004. Larval performance and oviposition site preference along a predation gradient. - Ecology 85: 2094-2099.

Schiesari, L. C. 2004. Performance tradeoffs across resource gradients in anuran larvae. - PhD. thesis, Univ. of Michigan, Ann Arbor, MI.

Schiesari, L. C. et al. 2006. The growth-mortality tradeoff: evidence for anuran larvae and consequences to species distributions. - Oecologia 149: 194-202.

Schneider, D. W. and Frost, T. M. 1996. Habitat duration and community structure in temporary ponds. - J. N. Am. Benthol. Soc. 15: 64-86.

Semlitsch, R. D. et al. 1996. Structure and dynamics of an amphibian community: evidence from a 16-year study of a natural pond. - In: Cody, M. L. and Smallwood, J. A. (eds), Long-term studies of vertebrate communities. Academic Press, pp. 217-248.

Skelly, D. K. 2001. Distributions of pond-breeding anurans: an overview of mechanisms. - Isr. J. Zool. 47: 313-332.

Skelly, D. K. 2002. Experimental venue and estimation of interaction strength. - Ecology 83: 2097-2101.

Skelly, D. K. 2004. Microgeographic countergradient variation in the wood frog, Rana sylvatica. - Evolution 58: $160-165$. 
Skelly, D. K. et al. 1999. Long-term distributional dynamics of a Michigan amphibian assemblage. - Ecology 80: $2326-2337$.

Skelly, D. K. et al. 2002. Forest canopy and the performance of larval amphibians. - Ecology 83: 983-992.

Skelly, D. K. et al. 2003. Estimating decline and distributional change in amphibians. - Conserv. Biol. 17: 744751.

Skelly, D. K. et al. 2005. Canopy and amphibian biodiversity in forested wetlands. - Wetland Ecol. Manage. 13: 261268.

Smith, D. C. and Van Buskirk, J. 1995. Phenotypic design, plasticity, and ecological performance in 2 tadpole species. - Am. Nat. 145: 211-233.

Snodgrass, J. W. et al. 2000a. Development of expectations of larval amphibian assemblage structure in southeastern depression wetlands. - Ecol. Appl. 10: 12191229.

Snodgrass, J. W. et al. 2000b. Relationships among isolated wetland size, hydroperiod, and amphibian species richness: implications for wetland regulations. - Conserv. Biol. 14: 414-419.

Urban, M. C. 2004. Disturbance heterogeneity determines freshwater metacommunity structure. - Ecology 85: $2971-2978$

Uzzell, T. M. 1964. Relations of the diploid and triploid of the Ambystoma jeffersonium complex (Amphibia, Caudata). - Copeia 257-300.

Van Buskirk, J. 2005. Local and landscape influence on amphibian occurrence and abundance. - Ecology 86: 1936-1947.
Van Buskirk, J. and Arioli, M. 2005. Habitat specialization and adaptive phenotypic divergence of anuran populations. - J. Evol. Biol. 18: 596-608.

Waide, R. B. et al. 1999. The relationship between productivity and species richness. - Annu. Rev. Ecol. Syst. 30: 257-300.

Wellborn, G. A. et al. 1996. Mechanisms creating community structure across a freshwater habitat gradient. - Annu. Rev. Ecol. Syst. 27: 337-363.

Werner, E. E. and McPeek, M. A. 1994. Direct and indirect effects of predators on 2 anuran species along an environmental gradient. - Ecology 75: 1368-1382.

Werner, E. E. and Glennemeier, K. S. 1999. Influence of forest canopy cover on the breeding pond distributions of several amphibian species. - Copeia 1-12.

Werner, E. E. and Peacor, S. D. 2003. A review of traitmediated indirect interactions in ecological communities. - Ecology 84: 1083-1100.

Werner, E. E. et al. 2007. Turnover in an amphibian metacommunity: the role of local and regional factors. - Oikos 116: 1713-1725.

Wilbur, H. M. 1984. Complex life cycles and community organization in amphibians. - In: Price, P. W. et al. (eds), A new ecology: novel approaches to interactive systems. Wiley, pp. 195-224.

Wilbur, H. M. 1997. Experimental ecology of food webs: complex systems in temporary ponds - the Robert $\mathrm{H}$. Macarthur award lecture - presented 31 July 1995 Snowbird, Utah. - Ecology 78: 2279-2302.

Yurewicz, K. L. 2002. Size structure and intraguild interactions in larval salamanders. - PhD thesis, Univ. of Michigan, Ann Arbor, MI. 